\title{
In memoriam: Massimo Gallucci
}

\author{
Majda M Thurnher ${ }^{1}$ • On behalf of the ESNR Executive Committee and ESNR Members
}

Published online: 15 July 2015

(C) Springer-Verlag Berlin Heidelberg 2015

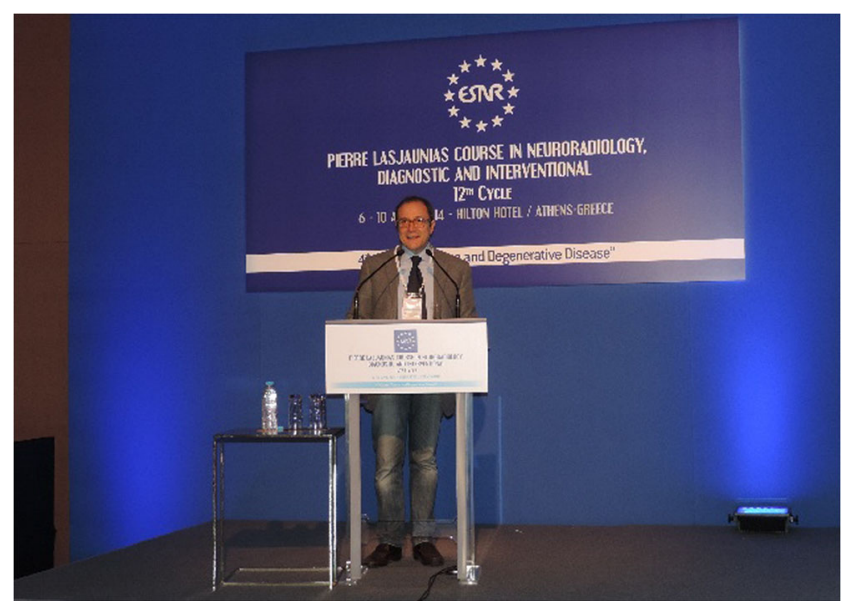

Massimo Gallucci passed away on May 15, 2015, after a long illness. He is survived by his daughters, Virginia and Lavinia, and wife Lucilla.

To write the obituary of a dear friend and colleague is to be on an emotional roller coaster from deep sorrow to warm memories. A professional résumé never captures the spirit of the person. Massimo had a big spirit. Massimo had a personality.

Massimo Gallucci was born on 18 February 1956 in L'Aquila, Italy. He finished medical school in 1980 and became a neurologist in 1984 and a board-certified radiologist in 1990. He was a full professor of neuroradiology at the School

Majda M Thurnher

majda.thurnher@meduniwien.ac.at

1 Department of Biomedical imaging and Image-guided Therapy, Medical University Vienna, Vienna, Austria of Medicine, University of L'Aquila, Italy, and professor of radiology, neuroradiology, and interventional radiology in nine postgraduate schools of specialization. He was the chairman of the Department of Neuroradiology at the S. Salvatore University Hospital of L'Aquila in Italy. He published more than 690 papers (among which were seven books, 59 papers in international journals, and 73 in Italian journals); he was an invited speaker at approximately 500 national and international meetings, the author of more than 450 scientific communications, and the organizer of 130 scientific meetings. He was a member of the Executive Committee of the Italian Society of Neuroradiology (AINR) (1989-2000), the Italian national delegate at the European Society of Neuroradiology (ESNR) (2000-2008), chairman of the National Delegate Council of the ESNR (2005-2008), president of the section of Neuroradiology of the Italian Society of Radiology (20082010), secretary general of the Division of Neuroradiology at UEMS (2008-2012), and a member of the commissions "Training" and "Medical Education" of the European Board of Neuroradiology (2006-2010). He also served on the editorial boards of the scientific journals Rivista di Neuroradiologia, Radiologia Medica, Neuroradiology Journal, and Neuroradiology. Together with Alex Rovira Cañellas, Massimo organized and very successfully revitalized the nineth and tenth cycles of the Pierre Lasjaunias European Course of Neuroradiology, effectively attracting hundreds of young radiological colleagues and physiciansin-training to our discipline. At the time of his passing, Massimo Gallucci was the incumbent president of the Italian Society of Neuroradiology, an office he took in 2013 and continued to hold until the very last with enormous bravery and dedication, despite his failing health.

Reading his own professional résumé on www.ilmiolibro. kataweb.it, compiled by himself, is a delight. It shows his sense of humor and, most notably, his genuine modesty. 
Massimo divides his profession into "desired profession:" Musician, Singer, and Writer, and "actual profession:" Full Professor of Neuroradiology. Under "social competences" Massimo writes: "no desire to speak about pointlessness." His answer to "other competences" is "limited." The last sentence of his biography is: "Altro? Ah... perdo i capelli" (Other? Ah... I am getting bald).

Massimo was a writer and a musician. His book "La Puntura di Atlante," awarded the second prize "Saturo d'Argento" in 2010, is an exciting thriller. His second book, "Nick," is a superb detective story with some strange coincidences, possibilities, comedy, science, fantasy, and even some esotericism. Another sense of delight "alla Massimo!"
On every February 18, which was his and also my birthday, I knew I would find an email with his birthday wishes. He never missed one.

When I was invited to lecture in his hometown of L'Aquila, he gave me a present, a book by Raffaele Morelli, "Le piccole cose che cambiano la vita" (Small things that change your life) and said: "Every day we need to think about small things, things that seem to be banal, because they can change our life, they can make you smile or cry, and at the end they will influence the big picture of our life."

Massimo Gallucci was a great scientist, one of the best neuroradiologists in Europe, a musician, a writer, and a dear friend.

Goodbye, Massimo. 